\title{
Overexpression of Rice Gene Lsi1 (Low Silicon Gene 1) Enhances The Plant-Microbe Interaction Resulting In Improved Chilling Tolerance
}

\section{Yuebin Xie ( $13426544042 @ 163 . c o m)$}

Fujian Agriculture and Forestry University

\section{Muhammad Umar Khan}

Fujian Agriculture and Forestry University

Chaojie Lan

Fujian Agriculture and Forestry University

Peiying Weng

Fujian Agriculture and Forestry University

Jingnan Zou

Fujian Agriculture and Forestry University

Xin Wu

Fujian Agriculture and Forestry University

\section{Wenxiong Lin}

Fujian Agriculture and Forestry University

\section{Zhong Li}

Fujian Agriculture and Forestry University https://orcid.org/0000-0001-7693-2486

\section{Research Article}

Keywords: Rice (Oryza sativa L.), Chilling, Proline, Osmotic balance, Microbe, Non-invasive Micro-test System

Posted Date: January 3rd, 2022

DOI: https://doi.org/10.21203/rs.3.rs-1204906/v1

License: (c) (i) This work is licensed under a Creative Commons Attribution 4.0 International License. Read Full License 


\section{Abstract}

Chilling is an environmental phenomenon that hampers the plant growth. Related studies are mainly on based on the aerial plant parts. While, below ground to rhizosphere microbiome have been neglected under low temperature stress. The overexpression of $L$ si 1 in Dular significantly enhances its proline concentration compared with wild type Dular. This overexpression phenomenon maintains the osmotic balance of cells through influx of $\mathrm{Ca}^{2+}, \mathrm{K}^{+}, \mathrm{H}^{+}$and efflux of $\mathrm{Na}^{+}$. The calcium deposition and the activity of plasma membrane $\mathrm{H}^{+}$-ATPase determined in root tip was consistent with the obtained ion flux results. In addition, the high-throughput sequencing results showed significant variation among identified 84 genera in different rhizocompartments (rhizosphere, rhizoplane and endosphere). The identified bacteria were associated with photosynthesis, energy metabolism, nitrogen fixation and defense, which were significantly increased in overexpressed plant. While, the number of pathogenic microorganisms associating were significantly reduced. Our findings suggests that the stability of ion balance in overexpressed plant roots affects the structure of microbial community in soil. To conclude, the over expression of $L$ si 1 gene enhanced cold tolerance of rice and its underlying mechanisms were comprehensively analyzed which can further impart its role in the stress tolerant rice plants.

\section{Introduction}

In China, during cold spell in the late spring especially in the month of April rice (Oryza sativa) seedling incurs the damages leading to yield reductions.(Fang et al, 2017b). To coupe the losses novel methods are required, such as development of cold tolerant rice varieties. Many studies suggest that elements such as Silicon ( $\mathrm{Si}$ ) play significant role in strengthening defense mechanisms of the plant (Mitani et al, 2005, Mitani et al, 2009). In rice, the silicon absorption is controlled by Low silicon gene 1 (Lsi1) which encodes a Nod26-like protein (NIP) subfamily (Ma et al, 2006). Specifically, the gene Lsi1 was first identified in a mutant rice with lower silicon absorption ability and it is constitutively expressed in plant roots (Ma et al, 2004). Accidentally, we found a feature of this overexpressed line that when the temperature fell lower than $15^{\circ} \mathrm{C}$, Wild type Dular (WT) showed obvious chilling damage (albino seedlings), while Lsi1-overexpression Dular (OS) remained bright green, which led us study the related mechanisms in depth. Moreover, our early studies confirmed that over-expression of $L$ si1 gene in Dular rice increased the cold tolerance by mediating both the transcriptional and proteomic regulatory networks (Fang et al, 2017a, Azeem et al, 2015). Nevertheless, the study of $L$ si1 gene in rice was focused on the above ground plant parts, the belowground research has not been reported. Therefore, it is crucial to reveal the root associated microbes response to cold in rhizosphere.

For the plants growing in the soil are in contact with diverse microorganism communities (Bulgarelli et al, 2013). In the rhizosphere stenosis area, there are a large number of microbial communities, in which the macrogenomic group of the rhizosphere microbial community is much larger and more complexity than the microbial community of the plant, it is referred as the second genome of the plant (Berendsen et al, 2012). Besides, the microbial community of a plant determines its health condition. Moreover, there are different studies on complexity of root microbial communities, comprising of rhizosphere associated 
microbes, genetic elements and their interactions. The high-throughput pyrosequencing technology has been widely used in studying the interaction between microorganisms and plants (Cole et al, 2009, Lozupone and Knight, 2005).

These studies further open a new avenue towards the plant microbial interactions, structure and the factors that affect them. However, there are no studies that conducted to understand how the microbial community response to cold in rice. Therefore, in consideration of above facts and based on our early results which indicate that $L$ si1 over expression enhances the cold tolerance in rice. In addition, previous studies also pointed out that the root ions in rice changed correspondingly under low temperature stress, which mediates increase in the cold tolerance in rice plants (Ma et al, 2015). Meanwhile, a large number of studies have confirmed the close relationship between root ion transport and microbial metabolism (Zhang et al, 2017, Shabala et al, 2009). As rice root ion transportation plays a role in rice root system to interact with microorganisms in the environment, we speculated that the over expression of Lsi1 may affect the ion transport balance of rice roots and mediate the microbial community distribution in the root environment.

We investigated the connection between ion transport and the associated root-microbes under cold stress. Besides, to further elucidate the ions balance required to maintain the cell membrane permeability, we employed the Non-invasive Micro-test Technology (NMT) to monitor the influx and efflux under. We mainly focused on $\mathrm{Ca}^{2+}, \mathrm{K}^{+}, \mathrm{Na}^{+}$and $\mathrm{H}^{+}$in OS root in comparison with WT. Moreover, we employed deep pyrosequencing of $16 \mathrm{~S}$ rDNA microbial gene to detect operational taxonomic units (OTUs), related to three distinct compartments (rhizosphere, rhizoplane, and endosphere). The large data sets from the WT and $L$ si 1 rice were used for identification of putative microbial interactions involved in processes to increase cold tolerance. Therefore, we provide insights into the ionic balance and process of root microbiome assembly in response to cold.

\section{Materials And Methods}

\section{Research material}

The study was carried out in the experimental field of Agricultural Ecological key laboratory, Fujian, China. Rice plants were cultivated in pots. The WT(Oryza sativa L., accession: Dular) and OS (cold tolereant) rice lines were used for all experiments in this study(Azeem., 2016; Fang et al., 2017; Fang et al., 2020). Plump rice seeds were disinfected with $25 \%$ sodium hypochlorite $(\mathrm{NaClO})$ solution for $15 \mathrm{~min}$, washed with deionized water, and then soaked in for $48 \mathrm{~h}$ to incubate at $28^{\circ} \mathrm{C}$ in dark and $85 \%$ relative humidity for 24 h. After germination, seeds were uniformly planted in the growing trays (the upper surface diameter 13 $\mathrm{cm}$; the lower surface diameter $8 \mathrm{~cm}$; height $7.5 \mathrm{~cm}$ ) containing matrix soil at $85 \%$ relative humidity and $28^{\circ} \mathrm{C}$ for $14 \mathrm{~h}$ with 20,000 Lux of light intensity, and then $22^{\circ} \mathrm{C}$ in dark for $10 \mathrm{~h}$. After the growth of one and half leaves, the planting conditions were adjusted to $15^{\circ} \mathrm{C}$ for $14 \mathrm{~h}$ with 20,000 Lux of light intensity, and then $10^{\circ} \mathrm{C}$ in dark for $10 \mathrm{~h}$ at $85 \%$ relative humidity. Meanwhile, normal plantings (control group) was 
set at regular temperature $\left(28^{\circ} \mathrm{C}\right.$ for $14 \mathrm{~h}$ with $20,000 \mathrm{Lux}$ of light intensity, and then $22^{\circ} \mathrm{C}$ in dark for $10 \mathrm{~h}$ at $85 \%$ relative humidity). After $48 \mathrm{~h}$ of treatment, samples were collected for subsequent analysis.

\section{Determination of proline (Pro) content}

$0.5 \mathrm{~g}$ rice roots were taken and placed in glass tubes, and then $5 \mathrm{~mL} 3 \%$ sulfosalicylic acid solution (3\% (W/V) sulfosalicylic acid, $100 \% \mathrm{H}_{2} \mathrm{O}$ ) was added to each tube respectively. Afterward, the tube was sealed with the bulb plug before starting extraction in boiling water bath for $10 \mathrm{~min}$. When it was cooled, the filtrate was filtered into clean glass tubes. $2 \mathrm{ml}$ extract was taken in another clean glass tube containing 2 $\mathrm{ml}$ glacial acetic acid and $2 \mathrm{ml} 2.5 \%$ acidic ninhydrin reagent (2.5\% (W/V) ninhydrin, 60\% glacial acetic acid, 40\% 6M phosphoric acid), and then heated it in water bath for 30min. After it was cooled, it was shaken for $30 \mathrm{~s}$ after addition of $4 \mathrm{~mL}$ toluene, and the components in the tube were let to sit for a sometime. The supernatant was shifted to $10 \mathrm{~mL}$ centrifugal tube, and centrifuged at 3,000 rpm for $5 \mathrm{~min}$. The supernatant was taken in a colorimetric cup. Toluene was used as a blank control, the absorbance value was measured at $520 \mathrm{~nm}$, and the concentration was calculated.

\section{Measurement of net $\mathrm{Ca}^{2+}, \mathrm{K}^{+}, \mathrm{Na}^{+}$and $\mathrm{H}^{+}$flux with the NMT system}

The net fluxes of $\mathrm{Ca}^{2+}, \mathrm{K}^{+}, \mathrm{Na}^{+}$and $\mathrm{H}^{+}$were measured by Non-invasive Micro-test Technology (NMT-YG100, Younger USA LLC, Amherst, MA 01002, Beijing, China). The influxes were measured with V2.0 (Younger USA LLC, Amherst, MA 01002, USA) Software (Zhao et al, 2015). This technique provides a high level of resolution and non-invasively method to measure different ions and small molecules in situ with working principle detailed in Li et al (Li et al, 2010). The root of rice plant was calibrated with measuring solution for $10 \mathrm{~min}$, then transferred to a small petri dish (6 cm diameter) containing $10 \mathrm{ml}$ of measuring solution. While, the roots were immobilized in petri dish containing measuring solution and microelectrode was vibrating between two positions i.e. $30 \mu \mathrm{m}$ from the root surface and kept perpendicular axis to the root. The background was recorded by vibrating the electrode in measuring solution without containing roots, then the electrode tip was filled with a commercially available ionophore $\left(\mathrm{Ca}^{2+}, \mathrm{K}^{+}, \mathrm{Na}^{+}\right.$and $\left.\mathrm{H}^{+}\right)$. The measuring solution for $\mathrm{Ca}^{2+}, \mathrm{H}^{+}$and $\mathrm{K}^{+}$contained a mixture $0.1 \mathrm{mM}$ $\mathrm{CaCl}_{2}, 0.1 \mathrm{mM} \mathrm{KCl}$ and 0.3mM 2-(N-Morpholino)ethanesulfonic acid (MES), pH 6.0. The measuring solutions for $\mathrm{Na}^{+}$consisted of $0.1 \mathrm{mM} \mathrm{CaCl}_{2}, 0.1 \mathrm{mM} \mathrm{KCl}, 0.1 \mathrm{mM} \mathrm{NaCl}$ and $0.3 \mathrm{mM} \mathrm{MES}, \mathrm{pH}$ 6.0.

\section{Assay of plasma membrane $\mathrm{H}^{+}$-ATPase activity}

Plasma membrane of rice root was prepared according the method of Xu et al. (Xu et al, 2012) and was stored at $-80^{\circ} \mathrm{C}$ until analysis. Bradford method was used to determine the protein concentration (Bradford, 1976). The $\mathrm{H}^{+}$-ATPase activity was determined in a reaction volume of $0.5 \mathrm{~mL}$ that contained $30 \mathrm{mM} \mathrm{BTP/MES,} \mathrm{pH} \mathrm{6.5,} 5 \mathrm{mM} \mathrm{MgSO}_{4}, 50 \mathrm{mM} \mathrm{KCl}$ and $4 \mathrm{mM}$ Tris-ATP and plasma membrane. The reaction continued for $30 \mathrm{~min}$ at $30^{\circ} \mathrm{C}$ and was stopped with $1 \mathrm{~mL}$ of stopping solution containing $2 \%$ (v/v) concentrated $\mathrm{H}_{2} \mathrm{SO}_{4}, 5 \%(\mathrm{w} / \mathrm{v})$ sodium dodecyl sulphate $0.7 \%(\mathrm{w} / \mathrm{v})$ sodium molybdate, followed by $50 \mathrm{~mL}$ of $10 \%(\mathrm{w} / \mathrm{v})$ ascorbic acid. Absorbance at $700 \mathrm{~nm}$ was measured with a spectrophotometer. 


\section{Calcium concentration}

The root tip selected was washed with $\mathrm{dd}_{2} \mathrm{O}$ before measuring the calcium concentration by as done by Qin (Qin et al, 2017). Briefly, the samples of root tip were incubated in solution containing $0.2 \mathrm{mM} \mathrm{CaC1}_{2}$,

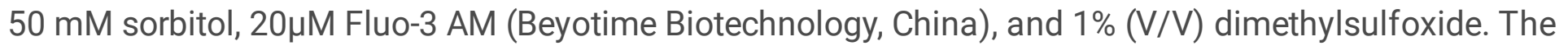
samples were wrapped in foil and incubated at $4^{\circ} \mathrm{C}$ for two hours, and washed twice with $0.2 \mathrm{mM} \mathrm{CaC1}_{2}$ solution and again incubated at room temperature for two hours then samples slides were observed under ten times fluorescence microscope (Nikon, Ni-U, Japan).

\section{Sampling and collection of the rhizocompartments}

Roots were collected from rice plants and soil is shaken off the roots to leave $1 \mathrm{~mm}$ of soil around the roots. The $1 \mathrm{~mm}$ of soil was washed off in PBS and kept as the rhizosphere soil. The clean roots were washed twice to remove remaining soil and placed into clean PBS in a $50 \mathrm{ml}$ falcon tube. The rhizoplane microbes were extracted by sonicating the roots with the rhizosphere compartment removed. The sonicated roots then placed in a new, clean falcon tube and sonicated twice more, the PBS in the tube discarded and refilled with clean PBS. These roots were then kept as endospheric sample (Edwards et al, 2015).

\section{DNA extraction, PCR amplification, PCR purification and pyrosequencing}

Total DNA of different rhizocompartments (Rhizsophere, rhizoplane and endosphere soil) was extracted by using Soil Gen DNA kit (CWBIO, Beijing, China) following the manufacturer's instructions. Nanodrop 2000C Spectrophotometer (Thermo Scientific, USA) was used to determine the DNA concentration and then DNA was diluted to $1 \mathrm{ng} / \mathrm{ul}$ using sterile water. Primer F (GTGCCAGCMGCCGCGGTAA) and $\mathrm{R}$ (GGACTACHVGGGTWTCTAAT) were used as amplified premer sequence. PCR reactions were carried out and PCR products were monitored on $2 \%$ agarose gel and samples containing bands between $400-450 \mathrm{bp}$ were selected for further analysis. Sequencing libraries were obtained by using TruSeq DNA PCR-Free Sample Preparation Kit (Illumina, San Diego, USA) following the manufacturer's instructions. Pyrosequencing was performed on an Illumina HiSeq2500 platform and 250 bp paired-end reads were generated.

\section{Operational Taxonomic Unit (OTU) analysis and Statistical Analysis}

The barcode and primer sequences were removed and raw tags of origin tag data were spliced using FLASH (V1.2.7) (Magoc and Salzberg, 2011). After chimera removal, the obtained sequences were denoted as effective tags and used to perform OTU cluster and species annotation. Sequences having $\geq$ $97 \%$ similarity was assigned in the same OTU using Uparse software (Uparse v7.0.1001) (Edgar, 2013).

The abundance of OTUs in each sample was homogenized than alpha and the beta diversity analysis were performed. The Observed-species, community richness indices Chao1, ACE, Shannon, Goods- 
coverage and PD_whole_tree indices were calculated by using Qiime software (Version 1.8). The R software (Version 2.15.3) was used to draw distribution curves and the differences among groups of Alpha diversity indices were analyzed. The function of microorganisms was predicted by FAPROTAX database and python 2.7 software. The principle coordinate analysis (PCoA) was carried out by using $R$ language program. One-way analysis of variance (ANOVA) followed by tukey's test $(P \leq 0.05)$ was performed for multiple comparison using DPS software version 7.51.

\section{Results}

\section{The OS and WT under chilling stress}

In order to gain insight about the ability of rice plants to eliminate ROS, we measured the proline (Pro) contents in both WT and OS at the low temperature and normal temperature. There was no significant difference in Pro content between the OS $\left(18.85 \mu \mathrm{g} \cdot \mathrm{g}^{-1} \cdot \mathrm{FW}\right)$ and WT $\left(19.39 \mu \mathrm{g} \cdot \mathrm{g}^{-1} \cdot \mathrm{FW}\right)$ at normal temperature (Figure 1). The content of Pro in OS and WT was significantly increased at low temperature than normal temperature, and the Pro content in OS $\left(41.32 \mu \mathrm{g} \cdot \mathrm{g}^{-1} \cdot \mathrm{FW}\right)$ was significant more than WT $\left(29.25 \mu \mathrm{g} \cdot \mathrm{g}^{-1} \cdot \mathrm{FW}\right)$, increased by $41.26 \%$ at low temperature. In addition, it also showed that the Pro content increased in OS plants under low temperature stress, which protected the cell membrane system from damage and enhanced the cold resistance of the plants.

\section{The fluxes of $\mathrm{Ca}^{2+}, \mathrm{K}^{+}, \mathrm{Na}^{+}$and $\mathrm{H}^{+}$in WT and OS}

To estimate the flow of some important ions involved in cold response, maintaining osmotic balance and defense signaling in roots, we used the NMT technology. There was no significant difference in $\mathrm{Ca}^{2+}, \mathrm{K}^{+}$, $\mathrm{Na}^{+}$and $\mathrm{H}^{+}$between WT and OS plants at normal temperature, and a small amount were excreted. There were significant differences observed in the fluxes of ions between the WT and OS (Figure 2 and 3 ). The flow rate of $\mathrm{Ca}^{2+}$ revealed that the roots of the OS plants assimilated greater $\mathrm{Ca}^{2+}$ as compared to WT. Besides, the roots of the WT plants absorbed $\mathrm{Ca}^{2+}$ and released $\mathrm{Ca}^{2+}$ occasionally. Furthermore, the OS plants showed absorption of $\mathrm{Ca}^{2+}$ as a whole, and the rate reached $54.31 \mathrm{pmol} / \mathrm{cm} / \mathrm{s}$. However, the WT plants showed efflux of $\mathrm{Ca}^{2+}$ as a whole, and the rate reached $0.92 \mathrm{pmol} \cdot \mathrm{cm}^{-2} \cdot \mathrm{s}^{-1}$. In addition, the OS roots showed significant absorption of $\mathrm{K}^{+}$and the rate reached $12.78 \mathrm{pmol} \cdot \mathrm{cm}^{-2} \cdot \mathrm{s}^{-1}$. However, the roots of the WT plants excreted a more quantity of $\mathrm{K}^{+}$, and the rate reached $157.02 \mathrm{pmol} \cdot \mathrm{cm}^{-2} \cdot \mathrm{s}^{-1}$. The flow rate of $\mathrm{Na}^{+}$shows that the roots of the OS plants excreted more $\mathrm{Na}^{+}$, and the rate reached 43.02 $\mathrm{pmol} \cdot \mathrm{cm}^{-2} \cdot \mathrm{s}^{-1}$ which was significantly different from the efflux in WT, which was $14.04 \mathrm{pmol} \cdot \mathrm{cm}^{-2} \cdot \mathrm{s}^{-1}$. Similarly, In Case of $\mathrm{H}^{+}$ions there distinct difference between OS (reached $10.21 \mathrm{pmol} \cdot \mathrm{cm}^{-2} \cdot \mathrm{s}^{-1}$ ) and WT $\left(0.09 \mathrm{pmol} \cdot \mathrm{cm}^{-2} \cdot \mathrm{s}^{-1}\right)$. These results depicts that under low temperature stress, OS plants absorbed $\mathrm{Ca}^{2+}$, $\mathrm{K}^{+}$and $\mathrm{H}^{+}$, while efflux of $\mathrm{Na}^{+}$was observed, which maintains the stability of cell membrane function, and enhance the cold resistance of the plants (reference).

\section{Measurement of Calcium deposition and $\mathrm{H}^{+}$-ATPase activity}


We found a lot of $\mathrm{Ca}^{2+}$ ions flow in both genotypes, for further confirmation, we measured the $\mathrm{Ca}^{2+}$ deposition in the root tips of WT and OS. And found that the OS contained higher deposition of $\mathrm{Ca}^{2+}$ than the WT under chilling stress, it indicated the involvement of $\mathrm{Ca}^{2+}$ in the cold response (Figure 4A). The results of ion absorption in this study also indicated that OS plants could absorb $\mathrm{Ca}^{2+}$ in a large amount under low temperature stress. The root calcium deposition experiment confirmed that the calcium content of OS roots was significantly higher than that of WT. Moreover, the $\mathrm{H}^{+}$-ATPase activity was also measured in the roots of both genotypes. The OS exhibited higher $\mathrm{H}^{+}$-ATPase activity than WT which increases the energy level for the influx and efflux of ions is OS (Figure 4B).

\section{OTU cluster and species annotation}

Soil bacterial community related to WT and OS defense against cold was unraveled by utilizing deep 16s rDNA pyrosequencing. Across all soil samples, a total of 1,457,835 effective tags containing species annotation was identified, with an average of 76,606 effective tags per sample. Among total effective tags, 40,400 singletons, accounting for $2.9 \%$ of total tags, were removed before further analysis (Figure S1). Rarefaction curves demonstrated the sequencing depth, the number of observed species numbers as shown in Figure S2. At a 97\% sequence similarity cut-off, we obtained a sum of 54,655 OTUs across the 18 samples. The OTUs numbers in WT R, WT RS, WT N, OS R, OS RS and OS N plots were 3,132, 3,023, $2,905,3,535,3,411$ and 2,212 , respectively. On average, we were able to classify about $99.4 \%, 97.9 \%$, $94.3 \%, 85.3 \%, 62.8 \%$ and $23.2 \%$ of effective sequences at the phylum, classes, orders, families, and genus and species level, respectively.

\section{Alpha Diversity Indices}

Alpha diversity was determined to further investigate species diversity within a sample. The Chao 1 estimator and the ACE were calculated to estimate the abundance of each sample. Both the Shannon and Simpson indices were determined to estimate the diversity within each individual sample. Besides, the bacterial community analysis showed that a significantly higher bacterial diversity was observed in OS R and OS RS than WT R and WT RS. Whereas, less bacterial diversity was observed in OS N than WT N (P $\leq$ 0.05). Also, there was no significant differences in the identified bacterial species, Shannon, Simpson, Chao 1 and ACE diversity indices between WT R and WT RS ( $P>0.05)$. The richness indices including the Shannon, Simpson, Chao 1 and ACE indices in OS N were lower than other treatments. Both the species observed, Shannon, Simpson, Chao 1 and ACE diversity indices significantly reduced from OS R to OS N $(P \leq 0.05)$. However, only Shannon and Simpson diversity indices significantly reduce from WT R to WT $\mathrm{N}$ (Table 1). 
Table 1

Calculations of observed species, richness and diversity in different soil samples.

\begin{tabular}{|c|c|c|c|c|c|}
\hline Treatments & Observed species & Shannon & Simpson & Chao 1 & $A C E$ \\
\hline & $2686.33 b$ & $8.46 b$ & $0.992 a$ & $3058.32 b$ & $3126.70 \mathrm{bc}$ \\
\hline \multicolumn{6}{|l|}{ WT R } \\
\hline WT RS & $2604.67 b$ & $8.45 b$ & $0.991 a$ & $2966.30 b$ & $3038.65 b$ \\
\hline WT N & $2483.00 \mathrm{~b}$ & $7.85 \mathrm{c}$ & $0.982 b$ & $2827.76 b$ & $2900.83 b$ \\
\hline OS R & 3116.33a & $9.01 a$ & $0.994 a$ & $3485.23 a$ & $3536.36 a$ \\
\hline OS RS & 2976.33a & $8.67 b$ & $0.992 a$ & $3329.85 a$ & $3400.02 \mathrm{ab}$ \\
\hline OS N & $1873.67 c$ & $6.33 d$ & $0.934 \mathrm{c}$ & $2222.85 c$ & $2290.70 c$ \\
\hline \multicolumn{6}{|c|}{$\begin{array}{l}\text { Note: WT and OS represent the wild type and } \angle \text { si1-Overexpression Dular. RDRS and } N \text { represent } \\
\text { rhizosphere, rhizoplane and endosphere, respectively. Whereas, "a", "b", " } c \text { " and " } d \text { " shows significano } \\
\text { level at } P \leq 0.05 \text {. Different letters in columns show significant differences determined by Tukey's test } \\
(P \leq 0.05, n=3) \text {. }\end{array}$} \\
\hline
\end{tabular}

\section{Beta Diversity Indices}

Beta diversity indices were determined by the differences in bacterial community composition and structure between samples. In this study, the weighted Unifrac distance between WT R and WT RS was a minimum of 0.074 , but 0.151 in the OS R and OS RS, showed a higher similarity of the soil bacterial community between WT R and WT RS than OS R and OS RS. The weighted Unifrac distances between OS $\mathrm{N}$ vs OS R (0.322) and OS N vs OS RS (0.290) more than WT N vs WT R (0.268) and WT N vs WT RS (0.239), showed a higher difference of the soil bacterial community from the $R$ to $N$ in OS than WT. The weighted Unifrac distances between OS R vs WT R, OS RS vs OS RS and OS N vs WT N were 0.093, 0.108 and 0.231 , respectively. Which being reason for the highest difference of the soil bacterial community observed in $\mathrm{N}$ than others (R and RS) as shown in Figure S3.

\section{PCoA analysis}

PCoA was performed based on the weighted UniFrac distance. In addition, the PCoA analysis identified distinct differences in soil bacterial community structure between different treatments. Nevertheless, the first two components (PC1 and PC2) of PCoA explained $60.17 \%$ and $18.34 \%$ of the total bacterial community variations, respectively as shown in Figure 5. Furthermore, the PCoA analysis showed that the bacterial communities of WT N and OS N were far from other groups and OS N was most diverse among all groups.

\section{Analysis of bacterial communities}

The cold significantly changed the bacterial communities in rhizosphere compartments of OS and WT. We identified 52 phyla, however, majority of OTUs belonged to 10 phyla, accounting for more than $95 \%$ of 
the total, including Proteobacteria, Firmicutes, Bacteroidetes, Cyanobacteria, Acidobacteria, Chloroflexi, Verrucomicrobia, Actinobacteria, Planctomycetes and Gemmatimonadetes. The relative abundance of these phyla is shown in (Figure S4). The content of proteobacteria in WT was significantly lower in N than $\mathrm{R}$ and RS, but there were no significant differences identified between R and RS, whereas, the proteobacteria content in OS was higher in $\mathrm{N}$ and was significantly decreased from RS to R. While the content of firmicutes and Cyanobacteria in WT was significantly increased from R to N. Nevertheless, in OS the firmicutes decreased significantly from R to $\mathrm{N}$. While the Cyanobacteria increased from $\mathrm{R}$ to $\mathrm{N}$ as shown in Table S1.

\section{Venn diagram analysis of identified genera in OS as compared to WT}

We not only identified 84 bacterial genera from R, RS and $\mathrm{N}$ but also by Venn diagram analysis we detected the exclusive and shared genera between six different soil samples (Figure 6). The exclusive genera were 20, 18 and 30 in R, RS and N respectively. There were 8, 1 and 4 genera in common in $\mathrm{R}$ and $\mathrm{RS}, \mathrm{RS}$ and $\mathrm{N}, \mathrm{R}$ and $\mathrm{N}$ respectively, and 3 genera in common across in R, RS and $\mathrm{N}$.

\section{Analysis of dominant genera}

In this study, 84 bacterial genera have been identified in six different treatments were shown in heat map Figure 7. We classified the identified 84 genera into 10 functional categories, including denitrification (7.14\%), defense (5.95\%), azotification (8.33\%), photosynthesis (4.76\%), chemotrophy (11.9), energy (1.19\%), biodegradation (9.52\%), carbon metabolism (4.76\%), pathogenicity $(26.19 \%)$ and unknown (20.24\%). The distribution of microbial communities in R, RS and N were significantly different (Figure 8, S2).

The microorganism for denitrification and biodegradation were accumulated in WT N. On the contrary, the microorganism related to azotification and energy was accumulated in OS N. While the microorganism for defense and photosynthesis were accumulated in OS R, RS and N. Moreover, the pathogenicity related microorganisms were accumulated in WT RS and N. These results indicate that rice plants have a significant shaping effect on the composition and structure of microbial communities in the root environment. In contrast, the results of microbial community in the root environment also affect the growth and development of plants. OS plants can select and enrich a large number of beneficial microorganisms (defense, azotification, photosynthesis and energy) and block the invasion of harmful microorganisms under low temperature stress. These results indicate that rice plants have a significant shaping effect on the composition and structure of microbial communities in the root environment. Moreover, the results of microbial community in the root environment also affect the growth and development of plants.

The OS plants absorb $\mathrm{Ca}^{2+}, \mathrm{K}^{+}, \mathrm{H}^{+}$and excrete $\mathrm{Na}^{+}$thus making $\mathrm{OS}$ better equipped to maintain the stability of membrane function. Ion transport in the root system of rice not only an important way to regulate plant response to external low-temperature stress, but also an essential carrier material to 
mediate material exchange and energy flow between root system and soil (Figure 9). In brief, it can be considered as one of key factors that contributes to the microecological characteristics in different root environments of plants, and it could be the basis for the establishment of plant-microorganism interaction also.

\section{Discussion}

\section{The increase of proline content enhanced the cold resistance of rice}

Cold adversely effects plants growth and causes physiological dysfunction (Lukatkin et al, 2012, Kroemer et al, 2004). Plants may develop cold tolerance to some extent during initial responses to cold (Fowler and Thomashow, 2002). However, continued exposure to cold stress was considered disastrous for plant life. Silicon was reported of resisting the abiotic stresses such as cold, drought and metal toxicities (Muneer et al, 2017). Previous studies have found that the over expression of $L$ si1 in rice had developed significant resistance against cold (Fang et al, 2017a, Azeem et al, 2015). Under stress, a large amount of reactive oxygen species (ROS) are produced in plants. ROS as an important signaling molecule is involved in plant growth and development and response to various stresses (Apel and Hirt, 2004). When low temperature stress occurs, the ROS in rice starts to accumulate in large amounts, and the rice antioxidant system begins to work. Our previous study showed that OS plants produce large amounts of SODs, CAT, and PODs (Azeem et al, 2015). It was reported that Proline play roles in protecting enzymes from denaturantion and helps in stabilizing the machinery of protein synthesis, regulating the cytosolic acidity, enhancing water-binding capacity, and acting as a reservoir of carbon and nitrogen source (Liu et al, 2007). In this study, the proline content of OS plants was significantly higher than that of WT plants, which protected the root of rice system. In addition, it enhanced the activity of rice root protective enzyme, stabilizes the function of the cell membrane, improved storage of nutrients in the root system, effectively eliminated the damage of ROS to the plant body, and improved the cold resistance of the plants.

\section{The OS root ion dynamics and maintenance of ion balance in response to cold}

The cold severely damages the plant cell membrane and as a result the lipid membrane permeability increases, solute leakage occurs in the cell, which causes the water loss, the balance of plant cell material exchange with the surrounding environment is hence destroyed (Lyons and Raison, 1970). Therefore, it is important to know how OS maintains the activity of plasma membrane proton pump and regulates intracellular influx and efflux of important cold responsive ions, such as $\mathrm{Na}^{+}, \mathrm{K}^{+}, \mathrm{Ca}^{2+}$, and $\mathrm{H}^{+}$. Additionally, the balance of intracellular potassium and sodium depends on the "sodium potassium pump" on the cell membrane, namely $\mathrm{Na}^{+}-\mathrm{K}^{+}$ATP enzyme. Moreover, the increase of extracellular $\mathrm{Ca}^{2+}$ concentration can inhibit $\mathrm{K}^{+}$efflux, reduce intracellular $\mathrm{Na}^{+}$concentration, and improve the activity of $\mathrm{H}^{+}$ATPase on vacuolar membranes. Besides, Studies have confirmed that proton pump plays an important 
role in maintaining $\mathrm{K}^{+} / \mathrm{Na}^{+}$balance in plants (Niu et al, 1995). Higher proton pump activity can provide $\mathrm{H}^{+}$ electrochemical potential gradient for $\mathrm{Na}^{+} / \mathrm{H}^{+}$reversed transport, reduced plasma membrane depolarization, and limited $\mathrm{K}^{+}$efflux (Chen et al, 2010, Maathuis, 2006). Based on results obtained during this study we speculated that under cold stress, OS maintains intracellular $\mathrm{K}^{+} / \mathrm{Na}^{+}$balance mechanism by $\mathrm{Na}^{+}$efflux, which facilitates to avoid excessive accumulation of $\mathrm{Na}^{+}$in the cytoplasm. Another way could be due to the loss of inhibition of $\mathrm{K}^{+}$. $\mathrm{Ca}^{2+}$ plays an important role in the process of plant resistance, such as the stress signal transduction, metabolic control and protect film stability (Polisensky and Braam, 1996, Knight et al, 2010). Present study results show that under the cold processing OS rice roots of $\mathrm{Ca}^{2+}$ velocity showed a trend of internal flows, flow of $\mathrm{Ca}^{2+}$ to make free $\mathrm{Ca}^{2+}$ in roots increased. Therefore, it prevents the plasma membrane $\mathrm{H}^{+}$-ATPase depolarization, limits the $\mathrm{K}^{+}$efflux, in order to maintain the balance of the intracellular $\mathrm{Na}^{+} / \mathrm{K}^{+}$. Nevertheless, the calcium deposits and $\mathrm{H}^{+}$-ATPase activity in the OS root was significance higher than the WT, the result confirmed the ion dynamics data. Moreover, we found that the plasma membrane $\mathrm{H}^{+}$-ATPase activity was significantly higher than that of WT, which indicates that the plasma membrane $\mathrm{H}+$ pump activity of OS plants was significantly higher than that of WT plants under low temperature stress. However, under chilling stress, OS plants promote $\mathrm{Na}^{+}$efflux and increase a small amount of $\mathrm{K}^{+}$by increasing the activity of plasma membrane $\mathrm{H}^{+}$pump, which negates the loss of excessive $\mathrm{K}^{+}$. It shows the proton concentration gradient to $\mathrm{Na}^{+}$after improving the activity of plasma membrane $\mathrm{H}^{+}$pump. Furthermore, $\mathrm{H}^{+}$transmembrane reverses transport, or can also reduce plasma membrane depolarization and thus limits $\mathrm{K}^{+}$outflow. Numerous studies have indicated that exogenous $\mathrm{Ca}^{2+}$ can regulate the $\mathrm{Na}^{+} / \mathrm{H}^{+}$reverse transport system of plant cells to maintain intracellular $\mathrm{K}^{+} / \mathrm{Na}^{+}$balance (Sun et al, 2010). The results points towards that absorption of more $\mathrm{Na}+$ inhibited $\mathrm{Ca} 2+$ in WT. Membrane with the increasing $\mathrm{Na}^{+} / \mathrm{Ca}^{2+}$ ions ratio, led to damaged membrane integrity and functions, ultimately cell membrane permeability increased.

In brief, these results further confirm that $L$ si1 mediates ion transport and enhances chilling tolerance of plants.

\section{The rice microbial communities response to cold}

The formation of cold resistance in plants is a complex biological process, multiple factors interact and mutually influence including plant and its underground soil microbiome. Exploring the process of plantmicrobe interactions and its regulatory mechanisms play an important role in studying the interrelationship between soil microbes and plant growth and development (Bais et al, 2004). Besides, studies have shown that different plants exhibit unique and representative rhizosphere microbial communities (Berendsen et al, 2012). The difference in root ion absorption leads to differences in plant growth and development, which in turn affect the microbial community composition.

In Arabidopsis, characterization of the diversity of core root microbial confirmed that endosphere microbial population is less than the rhizosphere, rhizoplane microbiomes (Haas et al, 2011). The OS has the higher abundance of Proteobacteria in N than the R and RS while in WT its abundance was more in 
the R and RS and less in N. This could be one of the reasons that helped the OS to develop resistance against the cold. Furthermore, PCoA analysis showed a distinct separation among all the soil samples especially between the WT N and OS N samples, suggesting the strong relationship between the plant performance and soil microbial community. In addition, OS $\mathrm{N}$ had significantly higher microbial diversity than the WT N. A higher microbial diversity is considered to be responsible for the development and maintenance of disease suppressive soils (Qiu et al, 2012, Yuan et al, 2014, Bruggen and Semenov, 2000). The OS rice plants had a significant effects on microbial community composition and structure in different soil layers under low temperatures.

Moreover, we found the significant variability in patterns of relative abundance of genera between the soil compartments of WT and OS. The identified 84 bacterial genera have been classified in to 10 functional classes. Among these soil borne microorganisms, certain groups of microorganisms were known to benefit the plants by, for example, supplying key plant nutrients such as nitrogen, phosphorus, protection against soil-borne diseases, and promoting resistance to abiotic stress (Berendsen et al, 2012). These beneficial microorganisms were collectively referred to as plant growth promoting rhizobacteria (PGPR) (Rameshkumar et al, 2016). Clostridium is a pathogenic bacterium that produces exotoxins and invasive enzymes (Kasai et al, 2005). Flavobacterium is a genus of gram-negative, non-motile and motile, rodshapedbacteria that consists of 130 recognized as disease causing species (Bernardet et al, 1996). The OS $\mathrm{N}$ accommodated less abundance of pathogenic bacteria and most of them were found in the OS $\mathrm{R}$ as compared to WT. As a result of that OS plants effectively avoided the invasion of pathogenic bacteria and ensured the stability of organism functions. Lysobacter can not only colonize the rhizosphere of many plants, but also secrete a variety of antibiotics (Md Tofazzal et al, 2005) and bioactive substances (Folman et al, 2003) to inhibit the growth of bacteria and control plant diseases (Jochum et al, 2006). It was led to the large presence of pathogenic bacteria in OS R and RS. The energy and azotification related bacteria found in OS $\mathrm{N}$ increase the nutrient and enhance the energy circulation of rice roots.

In brief, the OS $\mathrm{N}$ accommodates less abundance of pathogenic bacteria and most of them were found in the OS R as compared to WT. Whereas, OS N has higher proportions of photosynthetic, energy, azotification and defense microbes than RS and R, which ultimately enhancing its ability to tolerate cold. These results indicate that rice plants have a significant shaping effect on the composition and structure of microbial communities in the root environment. On the contrary, the results of microbial community in the root environment also affect the growth and development of plants. Based on microbial studies of $\mathrm{R}$ and $\mathrm{N}$, it has been proposed that the plants might accommodate the microbes in two steps, first thegeneral recruitment around the root and second step is on genetic basis (species specific) entry of microbes inside the root (Caporaso et al, 2010). We suggest that the rhizoplane plays a critical role to regulate the microbes transport which is adhered to the rhizosphere, few microbes can bound to the rhizoplane and fraction of them is allowed to enter and proliferate in endosphere. Each of these events involves complex molecular signals from plant, possibly the root exudates, cell membrane proteins, plant metabolites or cell wall components (Lundberg et al, 2012). 
Our study indicates that changes in root microbial community structure also have important effects on plant root absorption, energy flow, and the information transfer, which in turn affect plant growth and development. However, the rhizocompartments showed the largest variation in the comparison of OS and WT, suggesting the involvement of genotypic factors for microbes' recruitment. In summary, the shift in microbial diversity among each compartment indicates the two to three selective steps from root to interior and responding to multiple signals from the plant, coordinate the assembly of the root microbiome.

\section{Conclusion}

Our results suggest that the $L s i 1$ gene plays a pivotal role in response to the chilling tolerance. The NMT analysis showed that OS absorbed significant amount of $\mathrm{Ca}^{2+}, \mathrm{H}^{+}$and minute amount of $\mathrm{K}^{+}$. However, a large number of $\mathrm{Na}^{+}$effluent to maintain the balance of cell osmotic pressure. Calcium deposition method was used to find that the calcium content in the root of OS and it was significantly higher than WT, which confirmed our root ion absorption results of $\mathrm{Ca}^{2+}$. Additionally, the $\mathrm{H}^{+}$-ATPase activity on the root membrane in OS was significantly higher than that of WT, which indicated stronger energy metabolism of the plant and helped the plant to resist low temperature of external environment. Further, the results of high-throughput sequencing showed that the number of microorganisms associated with photosynthesis, energy metabolism, nitrogen fixation and defense was significantly up-regulated at low temperature, while the number of microorganisms associated with pathogenicity was significantly downregulated. Moreover, that over expressed plants can respond to stress in a timely manner under low temperature, and the plant itself can tolerate adverse conditions through a series of reactions. To conclude, the over expression of Lsi1 gene enhanced cold tolerance of rice and its mechanism were comprehensively analyzed, providing theoretical basis for the production of rice under spells of sudden temperature drop.

\section{Abbreviations}

OS Lsi1-overexpression Dular

WT Wild type Dular

Lsi1 Low silicon gene 1

NMT Non-invasive Micro-test Technology

R Rhizosphere

RS Rhizoplane

N Endosphere

Pro Proline 


\section{Declarations}

\section{Acknowledgements}

This work was supported by the National Key Research and Development program of China (2016YFD0300508), Fujian-Taiwan Joint Innovative Centre for Germplasm Resources and Cultivation of Crop (Fujian 2011 program, No. 2015-75) and the Natural Foundation of Fujian Higher Education Institutions for Young Scientists (Key Project) (JZ160435).

\section{References}

1. Apel K, Hirt H (2004) Reactive oxygen species: Metabolism, oxidative stress, and signal transduction. Annu Rev Plant Biol 55(1):373-399. https://doi.org/ 10.1146/annurev.arplant.55.031903.141701

2. Azeem S, Li Z, Zheng HP, Lin WW, Arafat Y, Zhang ZX, Lin XM, Lin WX (2016) Quantitative proteomics study on Lsi1 in regulation of rice (Oryza sativa L.) cold resistance. Plant growth regul 78(3):307323. https://doi.org/10.1007/s10725-015-0094-2

3. Bais HP, Park SW, Weir TL, Callaway RM, Vivanco JM (2004) How plants communicate using the underground information superhighway. Trends Plant Sci 9(1):26-32

4. Berendsen RL, Pieterse CMJ, Bakker PAHM (2012) The rhizosphere microbiome and plant health. Trends Plant Sci 17(8):478-486. https://doi.org/10.1016/j.tplants.2012.04.001

5. Bernardet JF, Segers P, Vancanneyt MBerthe F, Kersters K, Vandamme (1996) Cutting a gordian knot emended classification and description of the genus flavobacterium, emended description of the family flavobacteriaceae, and proposal of flavobacterium hydatis nom nov (basonym, cytophaga aquatilis strohl and tait 1978) [Revi. Int j system bacteriol 46(1):128-148

6. Bradford MM (1976) A Rapid and Sensitive Method for the Quantitation of Microgram Quantities of Protein Utilizing the Principle of Protein-Dye Binding. Anal Biochem 72(1-2):248-254. https://doi.org/ 10.1016/0003-2697(76)90527-3

7. Bruggen AHC, V, Semenov AM (2000) In search of biological indicators for soil health and disease suppression. Appl Soil Ecol 15(1):13-24. https://doi.org/ 10.1016/S0929-1393(00)00068-8

8. Bulgarelli D, Schlaeppi K, Spaepen S, van Themaat EVL, Schulze-Lefert P (2013) Structure and Functions of the Bacterial Microbiota of Plants. Annu Rev Plant Biol 64(1):807-838. https://doi.org/ 10.1146/annurev-arplant-050312-120106

9. Caporaso JG, Kuczynski J, Stombaugh J, Bittinger K, Bushman FD, Costello EK, Fierer N, Pena AG, Goodrich JK, Gordon JI, Huttley GA, Kelley ST, Knights D, Koenig JE, Ley RE, Lozupone CA, McDonald D, Muegge B, Pirrung D, Reeder M, Sevinsky J, Tumbaugh JR, Walters PJ, Widmann WA, Yatsunenko J, Zaneveld T, Knight J R (2010) QIIME allows analysis of high-throughput community sequencing data. Nat Methods 7(5):335-336. https://doi.org/ 10.1038/nmeth.f.303

10. Chen J, Xiao Q, Wu F, Dong X, He J, Pei Z, Zheng H (2010) Nitric oxide enhances salt secretion and $\mathrm{Na}(+)$ sequestration in a mangrove plant, Avicennia marina, through increasing the expression of 
$\mathrm{H}(+)$-ATPase and $\mathrm{Na}(+) / \mathrm{H}(+)$ antiporter under high salinity. Tree Physiol 30(12):1570-1585. https://doi.org/ 10.1093/treephys/tpq086

11. Cole JR, Wang Q, Cardenas E, Fish J, Chai B, Farris RJ, Kulam-Syed-Mohideen AS, McGarrell DM, Marsh T, Garrity GM, Tiedje JM (2009) The Ribosomal Database Project: improved alignments and new tools for rRNA analysis. Nucleic Acids Res 37:D141-D145. https://doi.org/ 10.1093/nar/gkn879

12. Edgar RC (2013) UPARSE: highly accurate OTU sequences from microbial amplicon reads. Nat Methods 10(10):996-998. https://doi.org/ 10.1038/nmeth.2604

13. Edwards J, Johnson C, Santos-Medellín C, Lurie E, Podishetty NK, Bhatnagar S, Eisen JA, Sundaresan $\mathrm{V}$ (2015) Structure, variation, and assembly of the root-associated microbiomes of rice. P Natl A Sci 112(8):E911-E920. https://doi.org/ 10.1073/pnas.1414592112

14. Fang C, Zhang P, Jian X, Chen W, Lin H, Li Y, Lin W (2017a) Overexpression of Lsi1 in cold-sensitive rice mediates transcriptional regulatory networks and enhances resistance to chilling stress. Plant Sci 262:115-126. https://doi.org/ 10.1016/j.plantsci.2017.06.002

15. Fang CX, Zhang PL, Jian X, Chen WS, Lin HM, Li YZ, Lin WX (2017b) Overexpression of Lsi1 in coldsensitive rice mediates transcriptional regulatory networks and enhances resistance to chilling stress. Plant Sci 262:115-126. https://doi.org/10.1016/j.plantsci.2017.06.002

16. Folman LB, Postma J, Veen JA (2003) Inability to Find Consistent Bacterial Biocontrol Agents of Pythium aphanidermatum in Cucumber Using Screens Based on Ecophysiological Traits. Microb Ecol 45(1):72-87

17. Fowler S, Thomashow MF (2002) Arabidopsis transcriptome profiling indicates that multiple regulatory pathways are activated during cold acclimation in addition to the CBF cold response pathway. Plant Cell 14(8):1675-1690

18. Haas BJ, Gevers D, Earl AM, Feldgarden M, Ward DV, Giannoukos G, Ciulla D, Tabbaa D, Highlander SK, Sodergren E, Methe B, DeSantis TZ, Human Microbiome Consortium, Petrosino JF, Knight R, Birren BW (2011) Chimeric 16S rRNA sequence formation and detection in Sanger and 454pyrosequenced PCR amplicons. Genome Res 21(3):494-504.

https://doi.org/10.1016/j.plantsci.2017.06.002

19. Jochum CC, Osborne LE, Yuen GY (2006) Fusarium head blight biological control with Lysobacter enzymogenes strain C3. Biol Control 39(3):336-344. https://doi.org/

10.1016/j.biocontrol.2006.05.004

20. Kasai Y, Kimura B, Kawasaki S, Fukaya T, Sakuma K, Fujii T (2005) Growth and toxin production by Clostridium botulinum in steamed rice aseptically packed under modified atmosphere. J Food Protect 68(5):1005-1011

21. Knight H, Trewavas AJ, Knight MR (1997) Calcium signalling in Arabidopsis thaliana responding to drought and salinity. Plant J 12(5):1067-1078

22. Kroemer K, Reski R, Frank W (2004) Abiotic stress response in the moss Physcomitrella patens: evidence for an evolutionary alteration in signaling pathways in land plants. Plant Cell Rep 22(11):864-870 
23. Li Q, LI B H, Kronzucker HJ, SHI WM (2010) Root growth inhibition by NH4+ in Arabidopsis is mediated by the root tip and is linked to $\mathrm{NH} 4+$ efflux and GMPase activity. Plant Cell Environ 33(9):1529-1542. https://doi.org/ 10.1111/j.1365-3040.2010.02162.x

24. Liu KM, Wang L, Xu YY, Chen N, Ma QB, Li F, Chong K (2007) Overexpression of OsCOIN, a putative cold inducible zinc finger protein, increased tolerance to chilling, salt and drought, and enhanced proline level in rice. Planta 226(4):1007-1016

25. Lozupone C, Knight R (2005) UniFrac: a new phylogenetic method for comparing microbial communities. Appl Environ Microb 71(12):8228-8235

26. Lukatkin AS, Brazaityte A, Bobinas $C$, Duchovskis $P$ (2012) Chilling injury in chilling-sensitive plants: a review. Zemdirbyste 99(2):111-124

27. Lundberg DS, Lebeis SL, Paredes SH, Yourstone S, Gehring J, Malfatti S, Tremblay J, Engelbrektson A, Kunin V, del Rio TG, Edgar RC, Eickhorst T, Ley RE, Hugenholtz P, Tringe SG, Dangl JL (2012) Defining the core Arabidopsis thaliana root microbiome. Nature 488(7409):86-. https://doi.org/ 10.1038/nature11237

28. Lyons JM, Raison JK (1970) Oxidative activity of mitochondria isolated from plant tissues sensitive and resistant to chilling injury. Plant Physiol 45(4):386-389

29. Ma JF, Mitani N, Nagao S, Konishi S, Tamai K, Iwashita T, Yano M (2004) Characterization of the silicon uptake system and molecular mapping of the silicon transporter gene in rice. Plant Physiol 136(2):3284-3289

30. Ma JF, Tamai K, Yamaji N, Mitani N, Konishi S, Katsuhara M, Ishiguro M, Murata Y, Yano M (2006) A silicon transporter in rice. Nature 440(7084):688-691

31. Ma Y, Dai XY, Xu YY, Luo W, Zheng XM, Zeng DL, Pan YJ, Lin XL, Liu HH, Zhang DJ, Xiao J, Guo XY, Xu SJ, Niu YD, Jin JB, Zhang H, Xu X, Li LG, Wang W, Qian Q, Ge S, Chong K (2015) COLD1 Confers Chilling Tolerance in Rice. Cell 162(1):222-222. https://doi.org/ 10.1016/j.cell.2015.01.046

32. Maathuis FJ (2006) The role of monovalent cation transporters in plant responses to salinity. J Exp Bot 57(5):1137-1147

33. Magoc T, Salzberg SL (2011) FLASH: fast length adjustment of short reads to improve genome assemblies. Bioinformatics 27(21):2957-2963. https://doi.org/ 10.1093/bioinformatics/btr507

34. Islam MT, Hashidoko Y, Deora A, Ito T, Tahara S (2005) Suppression of damping-off disease in host plants by the rhizoplane bacterium Lysobacter sp. strain SB-K88 is linked to plant colonization and antibiosis against soilborne Peronosporomycetes. Appl Environ Microb 71(7):3786-3796

35. Mitani N, Ma JF, Iwashita T (2005) Identification of the silicon form in xylem sap of rice (Oryza sativa L.). Plant Cell Physiol 46(2):279-283

36. Mitani N, Yamaji N, Ma JF (2009) Identification of maize silicon influx transporters. Plant Cell Physiol 50(1):5-12. https://doi.org/ 10.1093/pcp/pcn110

37. Muneer S, Park YG, Kim S, Jeong BR (2017) Foliar or Subirrigation Silicon Supply Mitigates High Temperature Stress in Strawberry by Maintaining Photosynthetic and Stress-Responsive Proteins. J Plant Growth Regul 36(4):836-845. https://doi.org/ 10.1007/s00344-017-9687-5 
38. Niu X, Bressan RA, Hasegawa PM, Pardo JM (1995) lon Homeostasis in NaCl Stress Environments. Plant Physiol 109(3):735-742

39. Polisensky DH, Braam J (1996) Cold-shock regulation of the Arabidopsis TCH genes and the effects of modulating intracellular calcium levels. Plant Physiol 111(4):1271-1279

40. Qin X, Wu H, Chen J, Wu L, Lin S, Khan MU, Boorboori MR, Lin W (2017) Transcriptome analysis of Pseudostellaria heterophylla in response to the infection of pathogenic Fusarium oxysporum. Bmc Plant Biol 17(1):155. https://doi.org/ 10.1186/s12870-017-1106-3

41. Qiu MH, Zhang RF, Xue C, Zhang SS, Li SQ, Zhang N, Shen QR (2012) Application of bio-organic fertilizer can control Fusarium wilt of cucumber plants by regulating microbial community of rhizosphere soil. Biol Fert Soils 48(7):807-816. https://doi.org/10.1007/s00374-012-0675-4

42. Rameshkumar N, Lang E, Tanaka N (2016) Description of Vogesella oryzae sp nov., isolated from the rhizosphere of saline tolerant pokkali rice. Syst Appl Microbiol 39(1):20-24. https://doi.org/ 10.1016/j.syapm.2015.10.003

43. Shabala L, McMeekin T, Shabala S (2009) Osmotic adjustment and requirement for sodium in marine protist thraustochytrid. Environ Microbiol 11(7):1835-1843. https://doi.org/ 10.1111/j.14622920.2009.01908.x

44. Sun J, Li LS, Liu MQ, Wang MJ, Ding MQ, Deng SR, Lu CF, Zhou XY, Shen X, Zheng XJ, Chen SL (2010) Hydrogen peroxide and nitric oxide mediate $\mathrm{K}+/ \mathrm{Na}+$ homeostasis and antioxidant defense in $\mathrm{NaCl}$-stressed callus cells of two contrasting poplars. Plant Cell Tiss Org 103(2):205-215. https://doi.org/ 10.1007/s11240-010-9768-7

45. Xu WF, Shi WM, Jia LG, Liang JS, Zhang JH (2012) TFT6 and TFT7, two different members of tomato 14-3-3 gene family, play distinct roles in plant adaption to low phosphorus stress. Plant Cell Environ 35(8):1393-1406. https://doi.org/ 10.1111/j.1365-3040.2012.02497.x

46. Yuan SF, Wang LL, Wu K, Shi JX, Wang MS, Yang XM, Shen QR, Shen BA (2014) Evaluation of Bacillus-fortified organic fertilizer for controlling tobacco bacterial wilt in greenhouse and field experiments. Appl Soil Ecol 75:86-94. https://doi.org/ 10.1016/j.apsoil.2013.11.004

47. Zhang YH, Sa G, Zhang YN, Zhu ZM, Deng SR, Sun J, Li NF, Li J, Yao J, Zhao N, Zhao R, Ma XJ, Polle A, Chen SL (2017) Paxillus involutus-Facilitated Cd2+ Influx through Plasma Membrane Ca2+Permeable Channels Is Stimulated by $\mathrm{H} 2 \mathrm{O} 2$ and H+-ATPase in Ectomycorrhizal Populus x canescens under Cadmium Stress. Front Plant Sci 7. https://doi.org/ 10.3389/fpls.2016.01975

48. Zhao R, Sun HM, Zhao N, Jing XS, Shen X, Chen SL (2015) The Arabidopsis Ca 2+-dependent protein kinase CPK27 is required for plant response to salt-stress. Gene 563(2):203-214. https://doi.org/ 10.1016/j.gene.2015.03.024

\section{Figures}




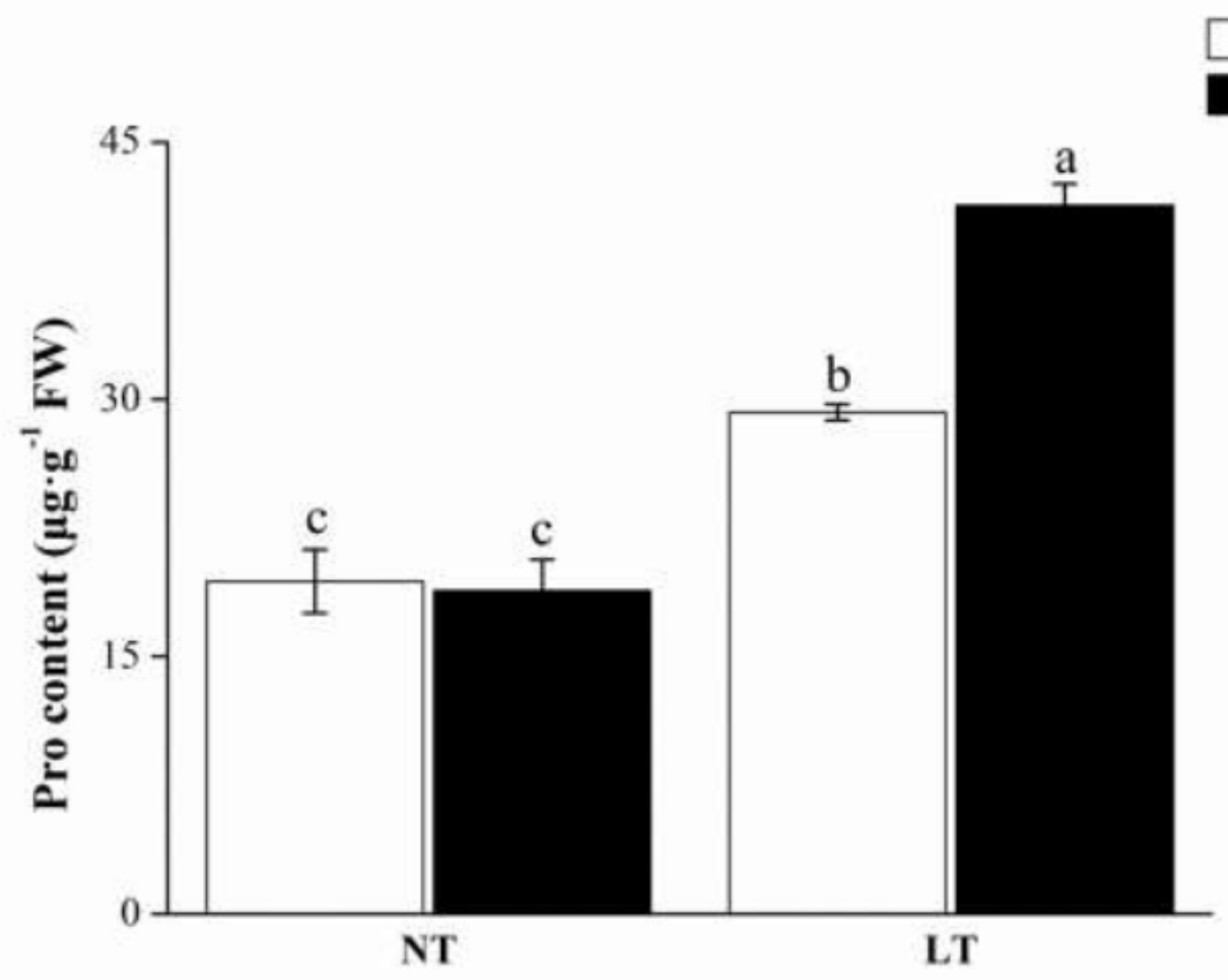

Figure 1

The Pro content in OS and WT roots. WT: Wild type Dular. OS: Lsi1-overexpression Dular. NT: Normal temperature. LT: Low Temperature. Whereas, "a" and " $b$ " shows significance level at $P \leq 0.05$ between OS and WT. Vertical bars represent standard error of the mean $(n=3)$ where these exceed the size of the symbol. 

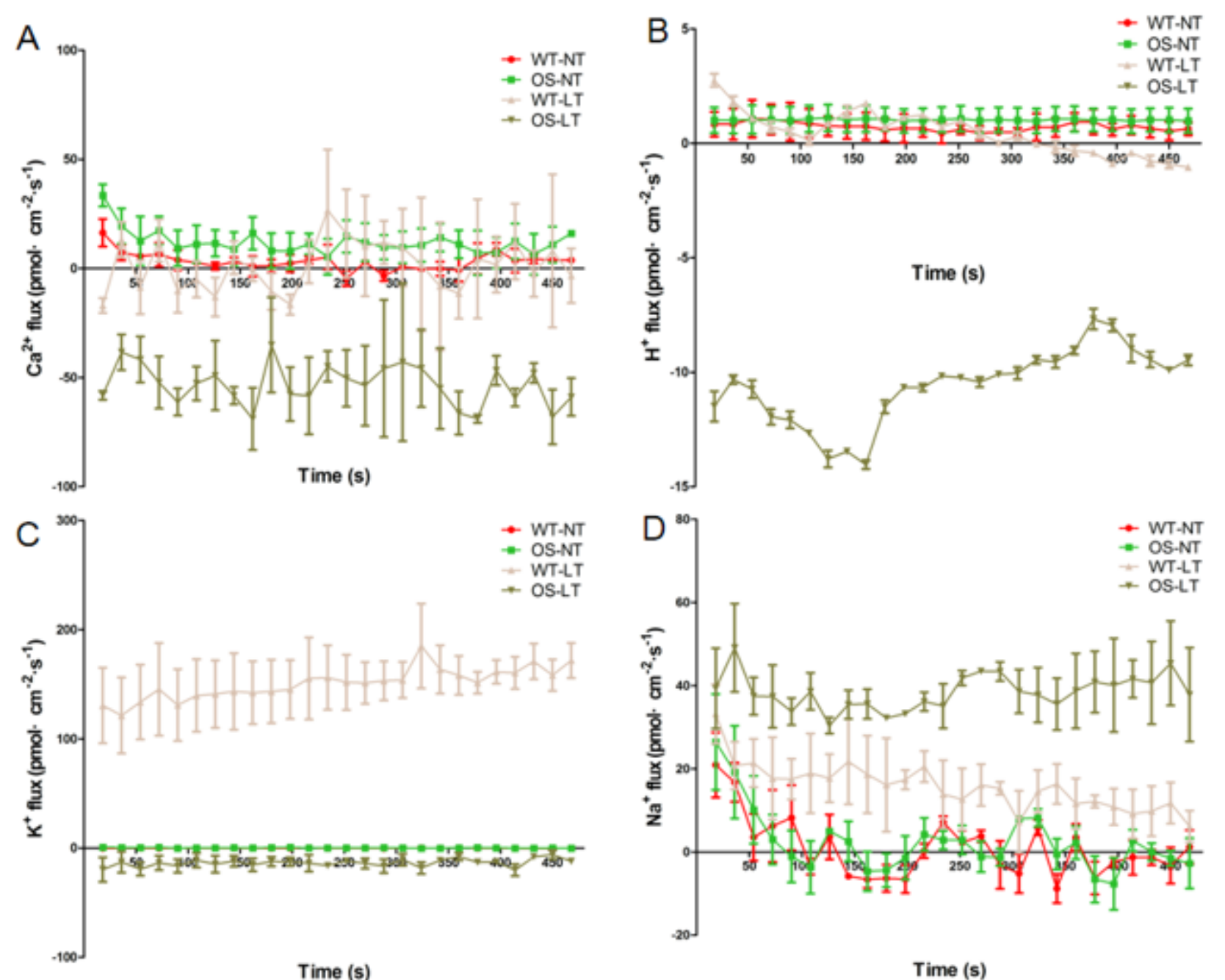

Time (s)

Figure 2

The influx and efflux of $\mathrm{Ca}^{2+}(\mathrm{A}), \mathrm{H}^{+}(\mathrm{B}), \mathrm{K}^{+}(\mathrm{C})$ and $\mathrm{Na}^{+}(\mathrm{D})$ in WT and OS. Vertical bars represent standard error of the mean $(n=3)$ where these exceed the size of the symbol. 

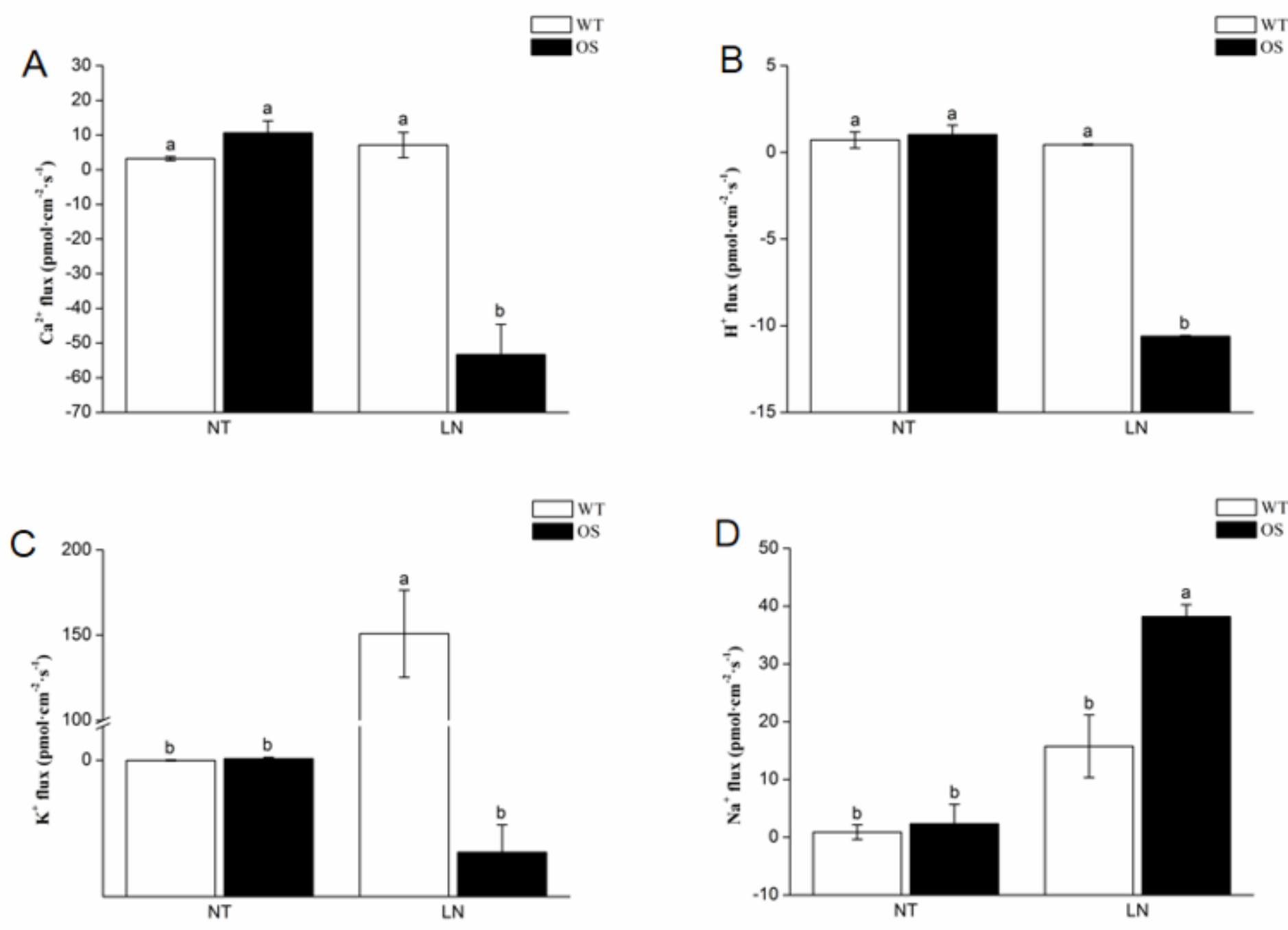

Figure 3

The average influx and efflux rates of $\mathrm{Ca}^{2+}(\mathrm{A}), \mathrm{H}^{+}(\mathrm{B}), \mathrm{K}^{+}(\mathrm{C})$ and $\mathrm{Na}^{+}(\mathrm{D})$ in WT and OS. Whereas, "a" and " $b$ " shows significance level at $P \leq 0.05$ between OS and WT. Vertical bars represent standard error of the mean $(n=3)$ where these exceed the size of the symbol.

Figure 4

The Calcium deposits (A) and $\mathrm{H}^{+}$-ATPase (B) activity in the root at low temperature. Whereas, "a" and "b" shows significance level at $P \leq 0.05$ between OS and WT. Vertical bars represent standard error of the mean $(n=3)$ where these exceed the size of the symbol. 


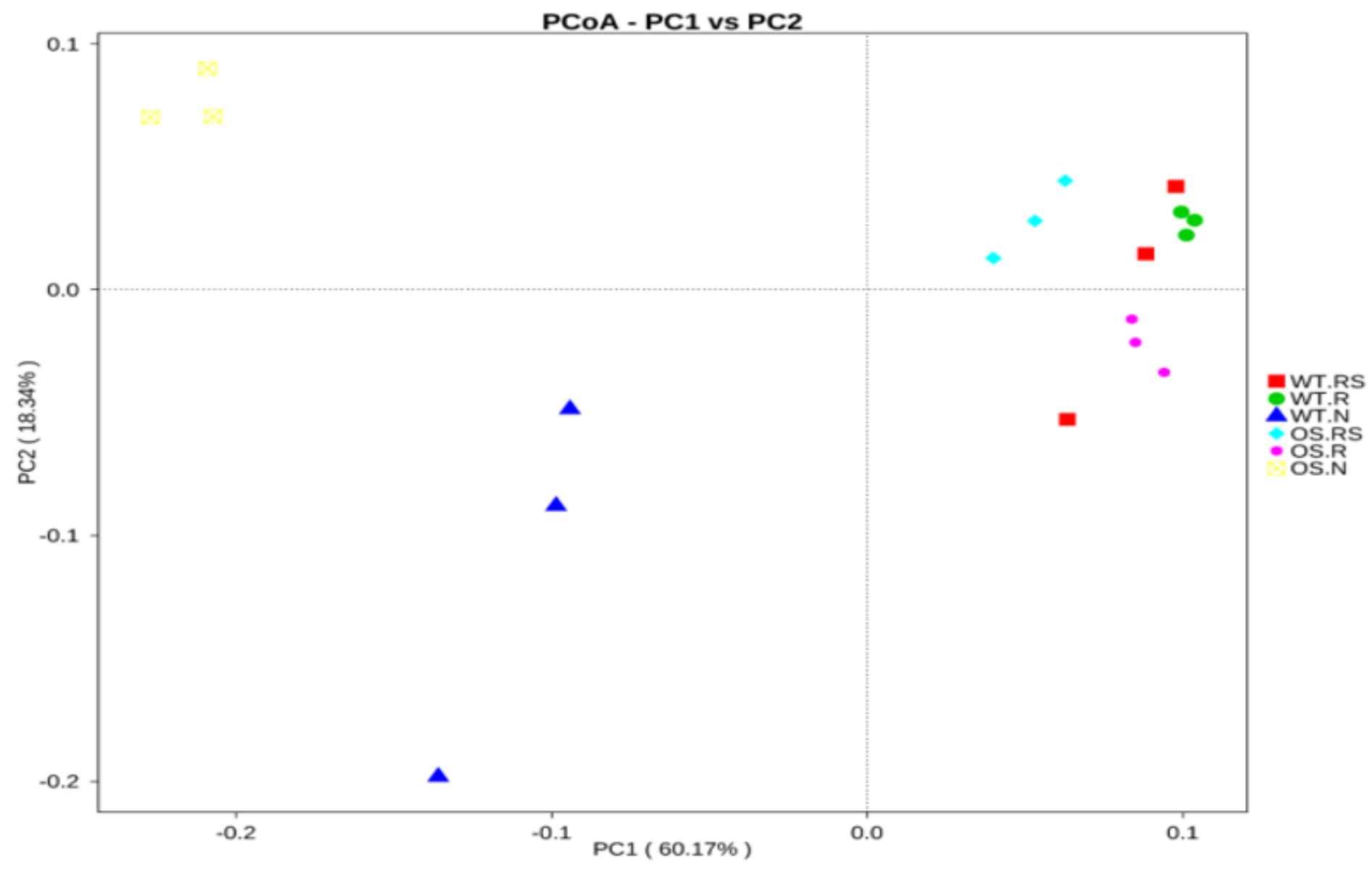

\section{Figure 5}

Principal coordinate analysis (PCoA) of bacterial communities based on weighted Unifrac algorithm for different soil samples.

\section{Figure 6}

Venn diagram analysis of identified exclusive and shared genera between the R, RS and N of OS compared with WT.

\section{Figure 7}

Heat map analysis of the 84 genera in six different treatments. Whereas, "a" , "b", "c" and "d" shows significance level at $P \leq 0.05$. Vertical bars represent standard error of the mean $(n=3)$.

Figure 8 
Functional classification of identified 84 bacterial genera (A). The expression of identified 84 bacterial genera in six different soil samples (B).

\section{Figure 9}

Schematic pathway is depicting the overexpression of rice gene $L$ si1 mediate the plant- microbe interaction resisting to chilling.

\section{Supplementary Files}

This is a list of supplementary files associated with this preprint. Click to download.

- supplementary.docx 